\title{
Validation of living with chronic illness scale in a type 2 diabetes mellitus population
}

\author{
Jorge Caro-Bautista' ${ }^{1}$, Carmen Rodríguez-Blázquez² , David Perez-Manchon ${ }^{3}$, Eva Timonet-Andreu 4 , \\ Gloria Carvajal-Carrascal ${ }^{5}$, Alejandra Fuentes-Ramírez ${ }^{5}$, Silvia Corchon ${ }^{6}$, Marta Aranda-Gallardo ${ }^{7}$ and \\ Leire Ambrosio ${ }^{8^{*}}$ (1)
}

\begin{abstract}
Background: Worldwide, type 2 diabetes mellitus (T2DM) is one of the most prevalent chronic diseases and one of those producing greatest impact on patients' day-to-day quality of life. Our study aim is to validate the "Living with Chronic Illness Scale" for a Spanish-speaking T2DM population.

Methods: In this observational, international, cross-sectional study, 582 persons with T2DM were recruited in primary care and outpatient hospital consultations, in Spain and Colombia, during the period from May 2018 to June 2019. The properties analysed were feasibility/acceptability, internal consistency, reliability, precision and (structural) content-construct validity including confirmatory factor analysis. The COSMIN checklist was used to assess the methodological/psychometric quality of the instrument.

Results: The scale had an adequate internal consistency and test retest reliability (Cronbach's alpha =0.90; intraclass correlation coefficient $=0.96$, respectively). In addition, the instrument is precise (standard error of measurement $=3.34$, with values $<1 / 2 S D=8.52$ ) and correlates positively with social support (DUFSS) $\left(r_{s}=0.56\right)$, quality of life (WHOQOL-BREF) $\left(r_{s}=0.51-0.30\right)$ and ssatisfaction with life (SLS-6) $\left(r_{s}=0.50-0.38\right)$. The original 26-items version of the scale did not support totally the confirmatory factor analysis. The COSMIN checklist is favourable for all the properties analysed, although weaknesses are detected for structural validity.

Conclusions: The LW-CI-T2DM is a valid, reliable and accurate instrument for use in clinical practice to determine how a person's life is affected by the presence of diabetes. This instrument correlates well with the associated constructs of social support, quality of life and satisfaction. Additional research is needed to determine how well the questionnaire structure performs when robust factor analysis methods are applied.
\end{abstract}

Keywords: Long-term condition, Type 2 diabetes mellitus, Chronic illness, Study validation, COSMIN

\section{Background}

Human life expectancy has increased sharply during the last century, but in consequence chronic disease is more prevalent and patients are living longer with ill health [1]. Diabetes mellitus (DM) is one of the non-communicable

\footnotetext{
${ }^{*}$ Correspondence: lag1v19@soton.ac.uk

${ }^{8}$ School of Health Sciences, NIHR ARC Wessex, University

of Southampton, Building 67, University Road, SO171BJ Southampton, United Kingdom

Full list of author information is available at the end of the article
}

diseases that most prejudices patients' quality of life, and impacts directly on daily routines. In 2017 , according to the International Diabetes Federation (IDF), 451 million people had DM, and this figure is expected to rise to 693 million by 2045 . In the same year, five million deaths were attributed to DM, and worldwide 850 billion US dollars were spent on managing the disease [2]. The costs arising from DM are mainly due to the associated complications, chief among which are ischemic heart disease, stroke, diabetic foot and diabetic nephropathy [3, 4]. original author(s) and the source, provide a link to the Creative Commons licence, and indicate if changes were made. The images or other third party material in this article are included in the article's Creative Commons licence, unless indicated otherwise in a credit line to the material. If material is not included in the article's Creative Commons licence and your intended use is not permitted by statutory regulation or exceeds the permitted use, you will need to obtain permission directly from the copyright holder. To view a copy of this licence, visit http://creativecommons.org/licenses/by/4.0/. The Creative Commons Public Domain Dedication waiver (http://creativeco mmons.org/publicdomain/zero/1.0/) applies to the data made available in this article, unless otherwise stated in a credit line to the data. 
Socioeconomic factors such as gender, age, education, type of health insurance and the time of evolution since diagnosis are significantly associated with disease outcomes [5].

The impact of DM is not only physical but also psychosocial, as the disease requires comprehensive involvement by healthcare services, which must focus both on clinical symptoms and on how the patient copes with the disease [6]. In this field, organisations such as the European Association for the Study of Diabetes and the American Diabetes Association recommend that persons with type 2 diabetes mellitus (T2DM) should seek to achieve self-management on the basis of shared decisionmaking and on lifestyle modification [7].

Patients and healthcare providers do not always coincide in their perceptions of the disease, and therefore it is crucial to identify patients' needs to ensure that appropriate clinical care is received. From this perspective, and in accordance with the steps outlined in Rodgers' evolutionary concept analysis [8], we may consider the goal of living with one or more than one chronic illness, which has been defined as "a complex, dynamic, cyclical and multidimensional process with the final desired target being to achieve positive living" (page 7) [9]. Various instruments have been proposed to measure this or other concepts associated with managing chronicity. Some have evaluated specific constructs: for instance, the Minnesota Living with Heart Failure Questionnaire (MLHFQ) [10] and the Living with Chronic Obstructive Pulmonary Disease Questionnaire (LCOPD) [11] both address the patient's quality of life; the Chronic Pain Acceptance Questionnaire (CPAQ) [12] focuses on acceptance of the process; Brief-COPE [13] considers how the patient copes with the situation. Other considerations are taken into account in the Diabetes Self-Management Questionnaire (DSMQ) [14] and the Psychosocial Adjustment to Illness Scale (PAIS) [15]. They focused on the evaluation of similar concepts related to the daily living like quality of life (MLHFQ, LCOPD), acceptance the chronic condition (CPAQ), coping the disease (Brief-COPE) or psychosocial adjustment to the disease (PAIS). However, none of these instruments evaluates the concept of living with a chronic illness such as T2DM. In this sense, one recently-developed scale addresses the concept of living with chronic illness, incorporating a broad spectrum of attributes, including acceptance, coping, self-management, integration and adaptation to the disease $[9,16]$. This questionnaire, the Living with Chronic Illness (LWCI) (from Spanish: Escala de convivencia con un proceso crónico EC-PC) scale includes 26 items spanning the above-mentioned dimensions. The LW-CI scale has been validated in a wide Spanish-speaking population with Parkinson's disease and has adequate psychometric properties [17]. Its acceptability was later evaluated in a pilot study for other Spanish-speaking populations (with T2DM, heart failure -HF-, chronic obstructive pulmonary disease -COPD- or osteoarthritis), which showed that the instrument was viable and presented acceptable preliminary levels of validity [18]. The validation of this instrument for persons with T2DM will make it possible to identify the factors that determine whether a patient is living more or less positive with the disease, thus providing clinicians with valuable information enabling them to apply focused interventions.

\section{Methods \\ Design}

An observational, international and cross-sectional study (one point-in-time evaluation, with retest) was carried out. This study is part of a macro research project with the general aim to achieve a unique Spanish-speaking scale to evaluate the process of living with one or more than one long term condition (LTC), as T2DM, osteoarthritis, COPD, HF, high blood pressure, and Parkinson's disease $[17,18]$. In particular, the contribution of this manuscript in this field is to present the psychometric properties of the LW-CI-T2DM scale in a Spanish-speaking population.

\section{Sample, sampling and sample size}

A consecutive cases sampling $[19,20]$ was applied to participant identification.

The sample was composed by people living with T2DM from different primary and secondary healthcare centres and community groups from Spain and Colombia. Inclusion criteria were (a) patients with T2DM diagnosis made by a endocrinology or General Practitioner (GP), in any stage of the disease; (b) Colombian or Spanish nationality; (c) able to read and understand properly the questionnaires; and (d) non-hospitalized patient at the moment of the study. Exclusion criteria were (a) patients with cognitive deterioration, acute disorder and/or pharmacological effects that potentially could distort the objective of the study; (b) refusal to participate in the study and (c) not meeting established inclusion criteria.

Sample size was calculated according to the model proposed by MacCallum-Browne-Sugawara [21]. To test a five-factor model, assuming the null hypothesis of a mean square error of approximation (RMSEA) from 0.05 to 0.08 , a statistical power of 0.80 , an alpha value of 0.05 , with $205 \mathrm{df}$, a minimum sample size of 225 was required. This sample was over-estimated by $20 \%$ to cover possible losses. These calculations were carried out using STATISTICA 12 (Dell Software, Tulsa, OK). 


\section{Instruments}

A sociodemographic questionnaire was used to collect personal data of the patient living with T2DM related to gender, age, marital status, educational level and employment situation. Besides, T2DM related questionnaire was used in order to know age of diagnosis, disease duration, and type and duration of treatment for T2DM. As in other validation studies carried out in Spain and South America [17] in addition to sociodemographic and disease related data, the following Spanish versions of selfreported scales were also collected:

$L W-C I-T 2 D M$ [18] scale focused to measure living with LTC. It is 26 items distributed in the following 5 dimensions: acceptance (4 items), coping (7 items), selfmanagement ( 4 items), integration ( 5 items) and adjustment (6 items). It is a five-point Likert-scale ranging from 0 (nothing/never) to 4 (much/always) (except for the "acceptance" dimension, in which the score is reversed). The final score ranges from 0 and 104 (higher scores better living with the LTC).

- The Duke-UNC Functional Social Support Questionnaire (DUFSS) [22, 23] was used to evaluate social support of the patients' from their perspective. It is an 8-items that evaluates different dimensions of social support as confidant, affective and instrumental support. The score for each item varies from 1 (much less than I would like) to 5 (as much as I would like).

- The World Health Organization Quality of Life Instrument-Brief (WHOQOL-BREF) [24] was used to measure the quality of life of people living with T2DM. The WHOQOL-BREF is comprised by 24-items that evaluates physical health, psychological health, social relationships, and environment. Item response options range from 1 (very dissatisfied) to 5 (very satisfied/very good quality of life).

- The modified version of the Satisfaction with Life Scale [25] is a to evaluate satisfaction overall with life (item 1) and in regard to other five areas: physical, psychological wellbeing, social relations, leisure, and financial situation. Each item scores from 0 (unsatisfied) to 10 (totally satisfied).

- The Patient Based Global Impression of Severity Scale (PGIS) [26] was used to evaluate the patient global impression of severity of the T2DM. It is a sixpoint Likert-scale ranging from 0 (not ill at all) to 5 (extremely ill) according to the patient.

For this validation study, the Spanish version of the scales was used.

\section{Data collection}

Data collection was carried out between May 2018 and June 2019. The potential participants (people living with T2DM) filled in the scales during the consult with the endocrinology, GP, nurse specialist or primary care nurse. To ensure homogeneity and reproducibility of the procedure of data collection a standardized protocol was established with the following steps: explaining the research study; asking about doubts; reading out load instructions of the scales and its answer options; writing a check marc in the answer chosen by the patient; reading out load instructions of self-reported scales and giving participants time to complete it. The median time to complete all the measures was approximately 30-40 min.

Data collection related to test-retest was also protocolized to minimize potential random errors.

Patients were asked to answer a second time to the LWCI-T2DM at home. The LW-CI-T2DM was in an envelope with seal and the research postal direction in order to complete the questionnaire and send it in an easy and free way to the researchers. A minimum sample of 50 subjects and a time span of 7 to 10 days for the retest was planned.

\section{Data analysis}

Descriptive statistics (central tendency measures, proportions) were used to determine the sociodemographic and T2DM characteristics. Main data were ordinal or did not fit normal distribution. Therefore, non-parametric statistics were used.

For the following psychometric properties were tested in this LW-CI-T2DM validation study:

Feasibility and acceptability. Quality of data was considered satisfactory if $95 \%$ of the data were computable. The limit for missing data was $<5 \%$ [27]. Floor and ceiling effect were deemed acceptable if they were $<15 \%$ [28] and the skewness was expected between -1 to +1 [29].

Internal consistency was tested by Cronbach's alpha coefficient (criterion value >0.70) [30], item-total correlation (corrected for overlap; criterion value, $r_{s} \geq 0.30$ ) [31], inter-item correlation (criterion value, $r \geq 0.20$ and $\leq 0.75$ ) [32], and item homogeneity (criterion value $>0.30)$ [33].

Reproducibility (test-retest) was determined using weighted kappa (with quadratic weights) for items (standard: >0.41 moderate) [34] and intraclass correlation coefficient (one way, random effect; ICC) for domains and total score. Values $\geq 0.60$ were considered acceptable [35].

Precision was estimated by means of the standard error of measurement $\left(\mathrm{SEM}=\mathrm{SD}_{\text {pooled }} * \sqrt{ }\left[1-\mathrm{r}_{\mathrm{xx}}\right]\right)$, where $S D_{\text {pooled }}=\sqrt{\left(S D_{1}^{2}+S D_{2}^{2}\right) / 2}$ and $r_{x x}$ was the ICC of the 
test-retest. A SEM value $<1 / 2 \mathrm{SD}_{\text {pooled }}$ was used as criterion of acceptable precision [36, 37].

Construct validity. Confirmatory factor analysis (CFA) was applied to corroborate the original 5-factor matrix of the instrument, using the following parameters of indices of good fit: (CMIN/df) less than 5 (preferably less than 3), RMSEA less than 0.08 with the respective $90 \%$ $\mathrm{CI}$, comparative fit index (CFI) of more than 0.90, and goodness-of-fit index (GFI) of more than 0.90 [38]. CFA estimations were all standardized, which allowed that factor loading and covariance matrix to vary. For convergent validity, and according to a previous study of the scale in patients with Parkinson's disease [14], a moderate $\left(r_{s} \geq 0.35-0.50\right)$ or strong relationship $\left(r_{s}>0.50\right)$ [39] was hypothesized between LW-CI-T2DM and DUFSS, SLS-6, and WHOQOL-BREF, and a weak/moderate association with other variables of the study, as age, T2DM duration or treatment. Spearman rank correlation coefficients were obtained to this purpose.

Internal validity, defined as the inter-correlations between the LW-CI-T2DM dimensions (standard, $\left.r_{s}=0.30-0.70\right)$ [33] and known-groups validity for gender, treatment and PGIS scores were determined. MannWhitney and Kruskal-Wallis tests were used for groups comparison.

\section{COSMIN assessment}

The COSMIN Checklist (COnsensus-based Standars for the selection of health $\underline{\text { Measurement } \underline{\mathrm{IN}} \text { struments) and }}$ its extension for content validity, were used for assessing the final measurement properties of the instrument and the methodology [40, 41].

\section{Results}

582 people living with T2DM from Spain and Colombia were included in this first validation study, where the $52.6 \%$ of the sample were females with an average age of 64.15 ( $\mathrm{SD}=2.18$ ) (Fig. 1). The $57.5 \%$ were married, the $60.3 \%$ present primary studies showing a basic educational level and the $30 \%$ were actively working full time at the moment of the study. The mean age of T2DM duration was $10.25(\mathrm{SD}=9.51)$ and the mean age with treatment $7.86(\mathrm{SD}=7.80)$ (Table 1).

Results related to data quality showed the scale had 6 missing data. There were 2 missing data in Domain 2. Coping, one missing data in Domain 3. Self-management, and 3 missing data in Domain 5. Adjustment. Regarding to acceptability, floor and ceiling effects for the total score ranged between 0.2 and $1.7 \%$ respectively. Domains and total score of the LW-CI-T2DM did not show skewness.

Results related to internal consistency of the LW-CIT2DM showed that Cronbach's alpha was 0.90 for the total scale and for the domains ranged between 0.71

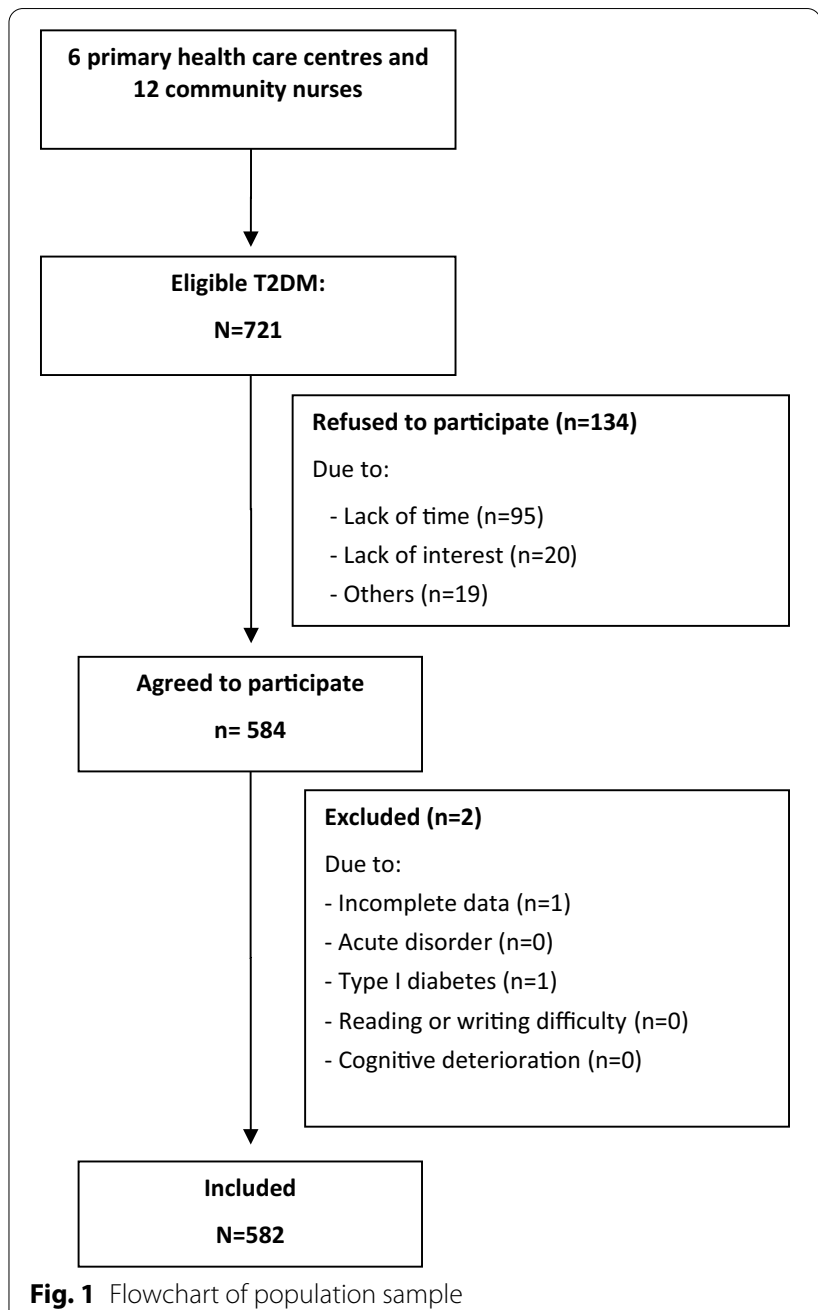

(Domain 3. Self-management) and 0.82 (Domains 1. Acceptance and 5. Adjustment). Item homogeneity ranged between 0.36 (Domain 4. Integration) and 0.53 (Domain 1. Acceptance). As it is showed in Table 2, all corrected item-total correlations were higher than established standard value.

Regarding the reproducibility of the LW-CI-T2DM (test-retest), this analysis was carried out in 135 patients living with T2DM. The ICC for the total scale was 0.96 and for all domains over 0.90 (Table 3). For individual items, weighted kappa ranged between 0.66 (item 24) and 0.88 (items 22).

SEM was 3.34 $\left(<\frac{1 / 2}{\mathrm{SD}}=8.52\right)$ for the total score of the scale and for the domains range from 0.92 to 1.52 (see Table 3).

Related to convergent validity, the LW-CI-T2DM presented strong relationship with DUFSS $\left(r_{s}=0.56\right)$, with SLS-6 $\left(r_{s}=0.50\right)$ and with Domain 2 of WHOQOL-BREF related to psychological health of the person $\left(r_{s}=0.51\right)$. Besides, the LW-CI-T2DM presented moderate 
Table 1 Characteristics of sample

\begin{tabular}{|c|c|c|c|c|}
\hline Sociodemographic characteristics & $\begin{array}{l}\text { Total sample } \\
N=582\end{array}$ & $\begin{array}{l}\text { Subsample Spain } \\
N=248\end{array}$ & $\begin{array}{l}\text { Subsample Colombia } \\
N=334\end{array}$ & $P$ value \\
\hline Female (\%) & $306(52.6)$ & $95(38.3)$ & $211(63.2)$ & $<0.001^{\mathrm{a}}$ \\
\hline \multicolumn{5}{|l|}{ Marital Status (\%) } \\
\hline Single & $87(15.0)$ & $34(13.9)$ & $53(15.9)$ & $<0.001^{\mathrm{a}}$ \\
\hline Married & $333(57.5)$ & $165(67.3)$ & $168(50.3)$ & \\
\hline Widower & $93(16.1)$ & $31(12.7)$ & $62(18.6)$ & \\
\hline Other & $66(11.4)$ & $15(6.1)$ & $51(15.3)$ & \\
\hline Occupation (\%) & & & & $<0.001^{\mathrm{a}}$ \\
\hline Active & $174(29.9)$ & $79(32.0)$ & $95(28.4)$ & \\
\hline Homemaker & $159(27.4)$ & $29(11.7)$ & $130(38.9)$ & \\
\hline Retired & $121(20.8)$ & $116(47.0)$ & $5(1.5)$ & \\
\hline \multicolumn{5}{|l|}{ Other } \\
\hline & $127(21.9)$ & $23(9.3)$ & $104(31.1)$ & \\
\hline Education (\%) & & & & $0.577^{a}$ \\
\hline None & $11(1.9)$ & $3(1.2)$ & $8(2.4)$ & \\
\hline Primary & $350(60.3)$ & $144(58.5)$ & $206(61.7)$ & \\
\hline High school & $134(23.1)$ & $61(24.8)$ & $73(21.9)$ & \\
\hline University & $85(14.7)$ & $38(15.4)$ & $47(14.1)$ & \\
\hline Insulin therapy (\%) & $268(51.5)$ & $69(37.1)$ & $199(59.6)$ & $<0.001^{\mathrm{a}}$ \\
\hline Age $($ mean $\pm S D)$ & $64.15(12.18)$ & $65.27(11.32)$ & $63.32(12,74)$ & $0.056^{\mathrm{b}}$ \\
\hline Time since diagnosis* & $10.25(9.51)$ & $11.49(10.54)$ & $9.34(8.56)$ & $0.007^{b}$ \\
\hline Time with insulin therapy* & $4.04(7.81)$ & $9.45(12.16)$ & $2.92(6.01)$ & $<0.001^{b}$ \\
\hline
\end{tabular}

$S D$ standar desviation

$P$ value between subsamples

* Years

a Chi test

b Mann-Whitney-Wilcoxon test

Table 2 Feasibility/Acceptability, reliability and precision of the LW-Cl-T2DM scale

\begin{tabular}{|c|c|c|c|c|c|c|}
\hline & \multicolumn{6}{|l|}{ LW-Cl-T2DM scale } \\
\hline & Domain 1. Acceptance & Domain 2. Coping & $\begin{array}{l}\text { Domain } 3 \text {. Self- } \\
\text { management }\end{array}$ & Domain. 4 Integration & Domain 5. Adjustment & Total score \\
\hline Mean (SD) & $11.53(3.74)$ & $18.80(5.56)$ & $11.00(3.37)$ & $14.82(3.66)$ & $15.35(5.45)$ & 71.53 (16.45) \\
\hline $\begin{array}{l}\text { Data Quality (\% fully } \\
\text { computable data) }\end{array}$ & 100 & 98 & 99 & 100 & 97 & 94 \\
\hline Floor effect (\%) & 1.0 & 0.5 & 0.7 & 0.2 & 0.5 & 0.2 \\
\hline Ceiling effect (\%) & 19.8 & 6.2 & 10.8 & 13.2 & 9.7 & 1.7 \\
\hline Skewness & -0.78 & -0.47 & -0.54 & -0.60 & $-0-24$ & -0.34 \\
\hline Cronbach's alpha & 0.82 & 0.77 & 0.71 & 0.72 & 0.82 & 0.90 \\
\hline Item-total correlation & $0.36-0.67$ & $0.21-0.50$ & $0.32-0.53$ & $0.16-0.58$ & $0.16-0.60$ & - \\
\hline Item homogeneity & 0.53 & 0.33 & 0.40 & 0.36 & 0.42 & - \\
\hline Reproducibility (ICC) & 0.93 & 0.93 & 0.90 & 0.91 & 0.96 & 0.96 \\
\hline $\begin{array}{l}\text { Precision (SEM) } \\
(1 / 2 \text { SD) }\end{array}$ & $\begin{array}{l}0.92 \\
(1.74)\end{array}$ & $\begin{array}{l}1.52 \\
(2.88)\end{array}$ & $\begin{array}{l}1.05 \\
(1.65)\end{array}$ & $\begin{array}{l}1.01 \\
(1.68)\end{array}$ & $\begin{array}{l}1.08 \\
(2.71)\end{array}$ & $\begin{array}{l}3.34 \\
(8.52)\end{array}$ \\
\hline
\end{tabular}

LW-CI-T2DM: Living with type 2 diabetes mellitus scale

$S D$ standard deviation, ICC intraclass correlation coefficient, SEM standard error of measurement $=S D_{\text {pooled }} * \sqrt{ }(1-I C C)$. 
Table 3 Convergent validity and internal validity of LW-CI-T2DM scale

\begin{tabular}{|c|c|c|c|c|c|c|}
\hline & \multicolumn{6}{|c|}{ LW-CI-T2DM scale } \\
\hline & $\begin{array}{l}\text { Domain } 1 . \\
\text { Acceptance }\end{array}$ & $\begin{array}{l}\text { Domain } 2 . \\
\text { Coping }\end{array}$ & $\begin{array}{l}\text { Domain 3. Self- } \\
\text { management }\end{array}$ & $\begin{array}{l}\text { Domain } 4 . \\
\text { Integration }\end{array}$ & $\begin{array}{l}\text { Domain } 5 . \\
\text { Adjustment }\end{array}$ & Total score \\
\hline \multicolumn{7}{|l|}{ Convergent validity } \\
\hline Age & $0.14^{* *}$ & -0.04 & -0.02 & 0.05 & -0.05 & 0.02 \\
\hline Age onset T2DM & $0.14^{* *}$ & $-0.1^{*}$ & -0.02 & 0.06 & -0.02 & 0.04 \\
\hline T2DM duration & $0.09^{*}$ & -0.08 & -0.01 & -0.02 & -0.04 & -0.10 \\
\hline WHOQOL_Physical health & $0.22^{* *}$ & $0.22^{* *}$ & $0.21^{* *}$ & $0.31^{* *}$ & $0.24^{* *}$ & $0.30^{* *}$ \\
\hline WHOQOL_Psychological & $0.23^{* *}$ & $0.44^{* *}$ & $0.40^{* *}$ & $0.48^{* *}$ & $0.45^{* *}$ & $0.51^{* *}$ \\
\hline WHOQOL_Social relationships & $0.19^{* *}$ & $0.31^{* *}$ & $0.27^{* *}$ & $0.40^{* *}$ & $0.32^{* *}$ & $0.38^{* *}$ \\
\hline WHOQOL_Environment & $0.22^{* *}$ & $0.32^{* *}$ & $0.34^{* *}$ & $0.49^{* *}$ & $0.34^{* *}$ & $0.43^{* *}$ \\
\hline DUFSS & $0.18^{* *}$ & $0.48^{* *}$ & $0.46^{* *}$ & $0.49^{* *}$ & $0.47^{* *}$ & $0.56^{* *}$ \\
\hline Satisfaction With Life & $0.28^{* *}$ & $0.34^{* *}$ & $0.36^{* *}$ & $0.47^{* *}$ & $0.40^{* *}$ & $0.50^{* *}$ \\
\hline Satisfaction_-physical health & $0.24^{* *}$ & $0.31^{* *}$ & $0.30^{* *}$ & $0.42^{* *}$ & $0.38^{* *}$ & $0.44^{* *}$ \\
\hline Satisfaction—well-being & $0.26^{* *}$ & $0.25^{* *}$ & $0.24^{* *}$ & $0.32^{* *}$ & $0.35^{* *}$ & $0.38^{* *}$ \\
\hline Satisfaction-social relations & $0.29^{* *}$ & $0.33^{* *}$ & $0.31^{* *}$ & $0.39^{* *}$ & $0.35^{* *}$ & $0.45^{* *}$ \\
\hline Satisfaction-leisure & $0.26^{* *}$ & $0.31^{* *}$ & $0.33^{* *}$ & $0.39^{* *}$ & $0.31^{* *}$ & $0.48^{* *}$ \\
\hline Satisfaction—financial situation & $0.19^{* *}$ & $0.35^{* *}$ & $0.30^{* *}$ & $0.41^{* *}$ & $0.29^{* *}$ & $0.41^{* *}$ \\
\hline \multicolumn{7}{|l|}{ Internal validity } \\
\hline Coping & $0.09^{*}$ & - & - & - & - & - \\
\hline Self-management & $0.17^{* *}$ & $0.61^{* *}$ & - & - & - & - \\
\hline Integration & $0.24^{* *}$ & $0.62^{* *}$ & $0.65^{* *}$ & - & - & - \\
\hline Adjustment & $0.13^{* *}$ & $0.62^{* *}$ & $0.56^{* *}$ & $0.59^{* *}$ & - & - \\
\hline
\end{tabular}

LW-CI-T2DM scale Living with type 2 diabetes mellitus scale

${ }^{* *} p<0.01 ;{ }^{*} p<0.05$

Table 4 Known-group validity

\begin{tabular}{lll}
\hline Categories & LW-Cl-T2DM total & $P$ value \\
\hline Sex & & \\
Men & $68.65(16.21)$ & $<0.001$ \\
Women & $74.12(16.28)$ & \\
Treatment for T2DM (insulin) & & \\
Yes & $72.45(16.49)$ & 0.09 \\
No & $69.75(16.70)$ & \\
PGIS-based severity levels & & $<0.001$ \\
None & $75.70(17.00)$ & \\
Mild & $71.31(15.65)$ & \\
Moderate & $71.52(15.61)$ & \\
Severe & $64.27(17.10)$ & \\
\hline
\end{tabular}

Mean (standard deviation)

LW-CI-T2DM Living with type 2 diabetes mellitus scale

correlations with all items of the SLS- 6 and Domains 3 and 4 of the WHOQOL-BREF related to social relationships and environment, respectively. Weak correlation was found with T2DM duration and physical health of the patient (see Table 3). According to internal validity, domains inter-correlated from 0.09 (Acceptance with
Coping) to 0.65 (Self-management and Integration). See Table 3 for further detail. In relation to known-group validity, results showed that total scores were significantly different for gender (higher in women) and for PGIS (see Table 4).

The CFA did not support the original 5-dimension model with 26 items. However, after analyzing residual errors in the standardized matrix of residual covariance, a final structure with 5 factor and 23 items showed better fit. Good indices were obtained: $\mathrm{CMIN} / d f=3.11$; goodness of fit index $=0.91$; comparative fit index $=0.91$ and root mean square error of approximation $=0.06(90 \%$ confidence interval, 0.06-0.07) (a complete description of the fit is available as Additional file 1).

\section{COSMIN results}

Five psychometric properties are addressed in the LWCI-T2DM scale (Boxes A-E of the COSMIN checklist). The instrument obtains acceptable results for internal consistency, measurement error, reliability and structural (construct) validity. The content validity lacked information from patients and healthcare professionals. This shortcoming is reflected in the COSMIN extension on the evaluation of the development quality of the Patient 
Reported Outcome (PRO) (a full description is available as Additional file 2).

\section{Discussion}

The aim of this study is to validate the Spanish version of the LW-CI scale for persons with T2DM, obtaining an instrument (LW-CI-T2DM) to measure how this population lives with the disease, with study outcomes that are useful both for researchers and in clinical practice.

Members of the research team have been working for several years to best define the concept of living with a chronic illness. For this purpose, an in-depth conceptual analysis was first performed [9], reviewing the literature on this question and making use of Rodgers' method of evolutionary concept analysis [8]. Before the psychometric evaluation, the questionnaire was piloted in various populations of persons with at least one chronic disease (including T2DM), to determine its viability and acceptability [18]. Many experts in the field consider this practice essential to ensure that the questionnaire items really address the construct that is to be measured [42].

In the present study, the non-response rate was less than $5 \%$ for all dimensions; there was no floor effect and in relation to the ceiling effect, only the $15 \%$ limit was exceeded, and that very slightly, for the "acceptance" dimension. These data suggest that, a priori, the scale provides reasonable acceptability [28].

LW-CI-T2DM has excellent internal consistency (Cronbach's alpha $=0.90$ ) both overall and for each dimension, always remaining within the recommended limits, which suggests there is no redundancy in the content of the questions [43]. Similarly, the questionnaire presents high reliability in the sub-sample selected for the retest, comfortably surpassing the minimum levels recommended (ICC>0.70) [43] despite its significant extension, with 26 items. These findings suggest that LWCI-T2DM is a parsimonious instrument, measuring the intended aspects of the question with the fewest items possible, a quality that is highly desirable [44].

The CFA did not support the original structure of the designed scale based on solid conceptual framework [9] and other validation studies carried out in patient with other chronic conditions such as Parkinson's disease [17]. A 23-item version adjusted better than the 26-item original version. However, based on previous conceptual and empirical findings $[9,17,18]$ as well as a research team consensus, further research to elucidate the final configuration of the scale, using a robust validation methodology such as Rasch analysis [45] is suggested. Nevertheless, the results emerged in this validation study will be carefully considered in further studies carried out in patient living with different chronic conditions, such as T2DM among others.
Finally, the instrument is precise and correlates positively, at least to a moderate degree, with the existence of social support and with each of the subdimensions of the scales measuring satisfaction and quality of life. The correlation data are similar to those reported for the population with Parkinson's disease [17], showing that the questionnaire measures these cross-sectional constructs in a similar way in each of these chronic conditions. However, we must consider this aspect with caution, because the measurement invariance between groups has not yet been established.

Application of the LW-CI-T2DM scale reveals significant differences according to the severity of the condition; thus, patients who are assigned higher scores (reflecting better coexistence with the disease) tend to be those who are less severely affected. Moreover, these scores are generally higher than those obtained by persons with Parkinson's disease, suggesting that living with T2DM is more tolerable. Differences by gender were also obtained, with higher scores for women. This finding differs from that produced by the pilot study, although this preliminary work included a population with other chronic diseases (COPD, HF or osteoarthritis) [18]. Other studies have shown that women with T2DM are at greater risk than men of psychosocial maladjustment, a poorer cardiovascular profile and/or non-compliance with treatment goals $[46,47]$. These outcomes are not consistent with our findings and further research is needed to clarify the question.

From a conceptual standpoint, the LW-CI-T2DM scale has similarities with constructs addressed by other theoretical models. Thus, dimensions such as self-management or coping bear an important relationship with Bandura's concept of self-efficacy [48], which is widely used by other instruments in psychosocial approaches to chronic diseases $[49,50]$. Other dimensions, such as integration or adaptation, are closely linked to the notion of perceived control, introduced by Ajzen in his Theory of Planned Behaviour (TPB) [51]. The instrument also correlates very reasonably with social support, a concept also introduced in the TPB as the subjective norm (perceptions of the impact of third parties-such as family, friends or healthcare professionals-on whether or not the conduct in question takes place). The use of a conceptual model to underpin the LW-CI-T2DM instrument enables the analyst to explain inductively how events happen and to suggest practical solutions to the problems encountered.

At the clinical level, the value of the instrument lies in its explanatory capacity, reflecting how a person with T2DM lives with the disease and thus allowing professionals to focus on the most troublesome aspects. This role is especially significant because healthcare 
professionals commonly express frustration at not achieving the expected results from treatment and recommendations. On the other hand, many patients believe their healthcare is not sufficiently individualised [52]. Prior analyses of patients with Parkinson's disease have shown that social support, followed by satisfaction with life and by socioeconomic status, are the only factors relevant to the patient's coexistence with the disease [53]. If these factors were equally influential with respect to T2DM, we would be facing a scenario in which social factors exerted significant influence on health conditions and should be taken into account when socio-health policies are designed and applied.

Although the present study has been performed with all possible rigour, it is subject to certain limitations. According to the International Society for Pharmacoeconomics and Outcomes Research (ISPOR), for an instrument to present content validity, it must obtain information derived from what is already known on the subject, from the reference population and from healthcare providers [54]. While LW-CI-T2DM is based on an important conceptual analysis of published research, the findings have not been triangulated with information obtained by qualitative techniques (via focus groups, cognitive interviews, the Delphi method, etc.), as described in the relevant section of the COSMIN checklist (Additional file 2). Furthermore, due to the innovative nature of the concept, LW-CI-T2DM lacks a gold standard with which to verify its criteria validity. However, other instruments have been proposed to evaluate psychosocial aspects of diabetes, such as the Problem Areas in Diabetes [55] and the Diabetes Empowerment Scale [56]. Although the approach they take is different from our own, it might be useful to analyse their possible correlations with LW-CI-T2DM scale. Finally, due to the intrinsic nature of the present research, the question of sensitivity to change has not been evaluated and as it is showed in COSMIN checklist (Additional file 2) structural validity have some flaws due to confirmatory factor analysis indices were not totally adequate.

\section{Conclusions}

LW-CI-T2DM is a valid, reliable and precise instrument for assessing the question of living with T2DM. Additional research is needed to identify the factors that specifically impact on the concept of "living with" this disease. In addition, more extensive analyses should be made of the construct under study, by robust methods such as evaluating its factor structure by means of structural equations.

\section{Abbreviations}

T2DM: Type 2 Diabetes Mellitus; COSMIN: Consensus-based Standars for the selection of health Measurement Instruments; DUFSS: Duke-UNC Functional Social Support Scale; WHOQOL-BREF: World Health Organization Quality of Life Instrument-Brief Scale; SLS-6: Satisfaction with Life Scale; PGIS: Patient Based Global Impression of Severity Scale; LW-Cl-T2DM: Living With Type 2 Diabetes Mellitus Scale; IDF: International Diabetes Federation; MLHFQ: Minnesota Living with Heart Failure Questionnaire; LCOPD: Living with Chronic Obstructive Pulmonary Disease questionnaire; CPAQ: Chronic Pain Acceptance Questionnaire; DSMQ: Diabetes Self-Management Questionnaire; PAIS: Psychosocial Adjustment to Illness Scale; LTC: Long term condition; GP: General Practitioner; ICC: Intraclass correlation coefficient; SEM: Standard error of measurement; SD: Standard desviation; PRO: Patient Reported Outcome; HF: Heart failure; COPD: Chronic obstructive pulmonary disease; TPB: Theory of Planned Behavior; PD: Parkinson's Disease; ISPOR: International Society for Pharmacoeconomics and Outcomes Research.

\section{Supplementary Information}

The online version contains supplementary material available at https://doi. org/10.1186/s12955-021-01715-x.

Additional file 1. Confirmatory factor analysis process.

Additional file 2. COSMIN assessment.

\section{Acknowledgements}

The authors sincerely thank all the patients with Type 2 Diabetes Mellitus for their participation in this study. Besides, the authors would like to thank the primary and secondary healthcare centres involved in the data collection in Spain and Colombia. In particular, the authors thank all the general and specialist nurses and physicians for their help in the data collection. The authors also appreciate the support in the data recruitment process received from the following multidisciplinary researchers: Lorena Lopez (Healthcare system of Madrid), Alfonso Meneses (Complutense University of Madrid), Nerea Elizondo (Navarra Healthcare system) Maria Victoria Navarta-Sanchez (Autonomous University of Madrid), Maria Eugenia Ursúa (Navarra Healthcare system), Manuel Ignacio Ruiz de Ocenda (La Rioja Healthcare system), and Neus Caparros (La Rioja University). Finally, the authors also thanks the financial support received from the Spanish Ministry of Economy, Industry and Competitiveness to carry out this project.

\section{Authors' contributions}

JC-B, CR-B and LA have made substantial contribution to the design of the work, conception, acquisition, analysis and interpretation of data and drafted the work. They have also approved the submitted version and agreed both to be personally accountable for the author's contributions and to ensure that questions related to the accuracy or integrity of any part of the work. DP-M, ET, GC-C, AF-R, SC, and MA-G have done the acquisition of the data, have approved the submitted version and have agreed both to be personally accountable for the author's own contributions and to ensure that questions related to the accuracy or integrity of any part of the work. All authors read and approved the final manuscript.

\section{Funding}

This study has been funded by the Ministry of Science, Innovation and University of the Spanish Government (FEDER/Ministerio de Ciencia, Innovación y Universidades-Agencia Estatal de Investigación/ Proyecto (CSO2017-82691-R)).

\section{Availability of data and materials}

The datasets used and/or analysed during the current study are available from the corresponding author on reasonable request. 


\section{Declarations}

\section{Ethics approval and consent to participate}

The study was approved by the Ethic Committee of University of Navarra in Spain (reference 2017.099) and the Ethic Committee of Universidad de La Sabana in Colombia (reference 013). Besides, this study ensured the compliance of the Declaration of Helsinki rules and the principles of Law 14/2007 on Biomedical Research and Law 15/1999 on Protection of Personal Data. All participants gave their signed consent to participate in a voluntary way in the study without any compensation for this after receiving the pertinent verbal and written information. All data and information related to the participant's identity was handled in full confidential way throughout the research process by the principal investigator.

\section{Consent for publication}

Not applicable.

\section{Competing interests}

The authors declare that they have no competing interests.

\section{Author details}

'Andalusian Public Health System, District of Primary Health Care of MálagaValle del Guadalhorce and Instituto de Investigación Biomédica de MálagaIBIMA, Málaga, Spain. ${ }^{2}$ National Centre of Epidemiology and CIBERNED, Carlos III Institute of Health, Madrid, Spain. ${ }^{3}$ Faculty of Health, Camilo José Cela University, Madrid, Spain. ${ }^{4}$ Department of Cardiology, Costa del Sol Hospital and Instituto de Investigación Biomédica de Málaga-IBIMA, Málaga, Spain. ${ }^{5}$ Facultad de Enfermería y Rehabilitación, Universidad de La Sabana, Chía, Colombia. ${ }^{6}$ Faculty of Nursing and Chiropody, University of Valencia, Valencia, Spain. ${ }^{7}$ Department of Internal Medicine, Costa del Sol Hospital, Marbella, Málaga, Spain. ${ }^{8}$ School of Health Sciences, NIHR ARC Wessex, University of Southampton, Building 67, University Road, SO171BJ Southampton, United Kingdom.

Received: 11 July 2020 Accepted: 23 February 2021

Published online: 17 March 2021

\section{References}

1. WHO. The Global Health Observatory data. Global Health Estimates: Life expectancy and leading causes of death and disability. Available at: https://www.who.int/gho/mortality_burden_disease/life_tables/situa tion_trends/en/ (2016). Accessed 02 Jun 2020.

2. Cho NH, Shaw JE, Karuranga S, Huang Y, da Rocha Fernandes JD, Ohlrogge AW, et al. IDF Diabetes Atlas: Global estimates of diabetes prevalence for 2017 and projections for 2045. Diabetes Res Clin Pract. 2018;138:271-81.

3. Jodar E, Artola S, Garcia-Moll X, Uría E, López-Martínez N, Palomino R, Martín V. Incidence and costs of cardiovascular events in Spanish patients with type 2 diabetes mellitus: a comparison with general population, 2015. BMJ Open Diabetes Res Care. 2020;8(1):e001130.

4. Tchero H, Kangambega P, Lin L, Mukisi-Mukaza M, Brunet-Houdard S, Briatte C. Cost of diabetic foot in France, Spain, Italy, Germany and United Kingdom: a systematic review. Ann Endocrinol. 2018;79(2):67-74

5. Wu H, Eggleston KN, Zhong J, Hu R, Wang C, Xie K, et al. How do type 2 diabetes mellitus (T2DM)-related complications and socioeconomic factors impact direct medical costs? A cross-sectional study in rural Southeast China. BMJ Open. 2018;8(11):e020647:1-11.

6. Halley MC, Petersen J, Nasrallah C, Szwerinski N, Romanelli R, Azar KM. Barriers and facilitators to real-world implementation of the diabetes prevention program in large healthcare systems: lifestyle coach perspectives. J Gen Intern Med. 2020;35(6):1684-92.

7. Buse JB, Wexler DJ, Tsapas A, Rossing P, Mingrone G, Mathieu C, et al. 2019 update to: Management of hyperglycaemia in type 2 diabetes, 2018. A consensus report by the American Diabetes Association (ADA) and the European Association for the Study of Diabetes (EASD). Diabetologia. 2020:63(2):221-8

8. Rodgers BL. Concept analysis: an evolutionary view. In: Concept development in nursing. Philadelphia: WB Saunders Company; 2000. p. 77-102.
9. Ambrosio L, Senosiain García JM, Riverol Fernández M, Anaut Bravo S, Díaz De Cerio Ayesa S, Ursúa Sesma ME, et al. Living with chronic illness in adults: a concept analysis. J Clin Nurs. 2015;24(17-18):2357-67.

10. Kularatna S, Senanayake S, Chen G, Parsonage W. Mapping the Minnesota living with heart failure questionnaire (MLHFQ) to EQ-5D-5L in patients with heart failure. Health Qual Life Outcomes. 2020;18(1):115.

11. McKenna SP, Meads DM, Doward LC, Twiss J, Pokrzywinski R, Revicki D, et al. Development and validation of the living with chronic obstructive pulmonary disease questionnaire. Qual Life Res. 2011;20(7):1043-52.

12. McCracken LM, Vowles KE, Eccleston C. Acceptance of chronic pain: component analysis and a revised assessment method. Pain. 2004;107(1-2):159-66.

13. Carver CS. You want to measure coping but your protocol's too long: consider the brief COPE. Int J Behav Med. 1997:4(1):92-100.

14. Schmitt A, Gahr A, Hermanns N, Kulzer B, Huber J, HaakT. The Diabetes Self-Management Questionnaire (DSMQ): development and evaluation of an instrument to assess diabetes self-care activities associated with glycaemic control. Health Qual Life Outcomes. 2013;11(138):1-14.

15. Rodrigue JR, Kanasky WF, Jackson SI, Perri MG. The Psychosocial Adjustment to IIIness Scale-Self-Report: factor structure and item stability. Psychol Assess. 2000;12(4):409-13.

16. Ambrosio L, Portillo MC. Tools to assess living with a chronic illness: a systematic review. Enferm Clin. 2018;28(4):220-9.

17. Ambrosio L, Portillo MC, Rodríguez-Blázquez C, Rodriguez-Violante M, Castrillo JCM, Arillo VC, et al. Living with chronic illness scale: international validation of a new self-report measure in Parkinson's disease. NPJ Parkinsons Dis. 2016;2(16022):1-6.

18. Ambrosio L, Navarta-Sánchez MV, Meneses A, Rodríguez-Blázquez C. Escala de convivencia con un proceso crónico: estudio piloto en pacientes con enfermedades crónicas. Aten Primaria. 2020:52(3):142-50.

19. Bowling A. Research methods in health: investigating health and health services. 4th ed. Open Berkshire: University Press; 2014.

20. Peduzzi P, Concato J, Kemper E, Holford TR, Feinstein AR. A simulation study of the number of events per variable in logistic regression analysis. J Clin Epidemiol. 1996:49(12):1373-9.

21. MacCallum R, Lee T, Browne MW. The Issue of isopower in power analysis for tests of structural equation models. Struct Equ Model: Multidisciplinary J. 2010;17(1):23-41

22. Ayala A, Rodríguez-Blázquez C, Frades-Payo B, Forjaz MJ, Martínez-Martín P, Fernández-Mayoralas G, et al. Psychometric properties of the Functional Social Support Questionnaire and the Loneliness Scale in non-institutionalized older adults in Spain. Gac Sanit. 2012;26(4):317-24.

23. Broadhead WE, Gehlbach SH, de Gruy FV, Kaplan BH. The Duke-UNC functional social support questionnaire. Measurement of social support in family medicine patients. Med Care. 1988;26(7):709-23.

24. Group TW. The World Health Organization quality of life assessment (WHOQOL): development and general psychometric properties. Soc Sci Med. 1998;46(12):1569-85.

25. Mazaheri M, Theuns P. A study of how satisfaction and dissatisfaction with life overall relate to satisfaction and dissatisfaction in specific life domains. Patient Reported Outcomes Newsl. 2006;37:24.

26. Guy W. ECDEU assessment manual for psychopharmacology-revised. Rockville: National Institute of Mental Health. Psychopharmacology Research Branch; 1976. p. 217-22.

27. Smith SC, Lamping DL, Banerjee S, Harwood R, Foley B, Smith P, et al. Measurement of health-related quality of life for people with dementia: development of a new instrument (DEMQOL) and an evaluation of current methodology. Health Technol Assess. 2005;9(10):1-93, iii-iv.

28. McHorney CA, Tarlov AR. Individual-patient monitoring in clinical practice: are available health status surveys adequate? Qual Life Res. 1995:4(4):293-307.

29. van der Linden FAH, Kragt JJ, Klein M, van der Ploeg HM, Polman $\mathrm{CH}$, Uitdehaag BMJ. Psychometric evaluation of the multiple sclerosis impact scale (MSIS-29) for proxy use. J Neurol Neurosurg Psychiatry. 2005;76(12):1677-81.

30. Aaronson N, Alonso J, Burnam A, Lohr KN, Patrick DL, Perrin E, et al. Assessing health status and quality-of-life instruments: attributes and review criteria. Qual Life Res. 2002;11(3):193-205.

31. Hobart JC, Riazi A, Lamping DL, Fitzpatrick R, Thompson AJ. Improving the evaluation of therapeutic interventions in multiple sclerosis: 
development of a patient-based measure of outcome. Health Technol Assess. 2004;8(9):iii, 1-48.

32. Piedmont RL. Inter-item correlations. Encyclopedia of quality of life and well-being research. 2014;3303-4.

33. Eisen M, Ware Jr JE, Donald CA, Brook RH. Measuring components of children's health status. Med Care. 1979;902-21.

34. Landis JR, Koch GG. The measurement of observer agreement for categorical data. Biometrics. 1977;159-74.

35. Cicchetti DV. Guidelines, criteria, and rules of thumb for evaluating normed and standardized assessment instruments in psychology. Psychol Assess. 1994;6(4):284.

36. lark LA, Watson D. Constructing validity: Basic issues in objective scale development. 2016 In A. E. Kazdin, editors. American Psychological Association. 2016. p. 187-203.

37. Norman GR, Sloan JA, Wyrwich KW. Interpretation of changes in healthrelated quality of life: the remarkable universality of half a standard deviation. Med Care. 2003;41(5):582-92.

38. Bollen KA, Long JS. Testing structural equation models. Available at: https ://us.sagepub.com/en-us/nam/testing-structural-equation-models/ book3893. Accessed 14 Sept 2020

39. Feeny D, Farris K, Côté I, Johnson JA, Tsuyuki RT, Eng K. A cohort study found the RAND-12 and Health Utilities Index Mark 3 demonstrated construct validity in high-risk primary care patients. J Clin Epidemiol. 2005;58(2):138-41.

40. Mokkink LB, Terwee CB, Patrick DL, Alonso J, Stratford PW, Knol DL, et al. The COSMIN study reached international consensus on taxonomy, terminology, and definitions of measurement properties for health-related patient-reported outcomes. J Clin Epidemiol. 2010;63(7):737-45.

41. Terwee CB, Prinsen CAC, Chiarotto A, Westerman MJ, Patrick DL, Alonso J, et al. COSMIN methodology for evaluating the content validity of patient-reported outcome measures: a Delphi study. Qual Life Res. 2018;27(5):1159-70.

42. Brod M, Tesler LE, Christensen TL. Qualitative research and content validity: developing best practices based on science and experience. Qual Life Res. 2009;1263-78.

43. Terwee CB, Bot SDM, de Boer MR, van der Windt DAWM, Knol DL, Dekker J, et al. Quality criteria were proposed for measurement properties of health status questionnaires. J Clin Epidemiol. 2007;34-42.

44. Rhodes RE, Plotnikoff RC, Spence JC. Creating parsimony at the expense of precision? Conceptual and applied issues of aggregating belief-based constructs in physical activity research. Health Educ Res. 2004;392-405.

45. Ambrosio L, Rodriguez-Blazquez C, Ayala A, Forjaz MJ. Rasch analysis of the Living with Chronic Illness Scale in Parkinson's disease. BMC Neurol. 2020;20(346):1-7.
46. Kautzky-Willer A, Harreiter J, Pacini G. Sex and Gender differences in risk, pathophysiology and complications of type 2 diabetes mellitus. Endocr Rev. 2016;37(3):278-316.

47. Penno G, Solini A, Bonora E, Fondelli C, Orsi E, Zerbini G, et al. Gender differences in cardiovascular disease risk factors, treatments and complications in patients with type 2 diabetes: the RIACE Italian multicentre study. J Intern Med. 2013;274(2):176-91.

48. Bandura A. Self-efficacy: toward a unifying theory of behavioral change. Psychol Rev. 1977;84(2):191-215.

49. Rapley P, Passmore A, Phillips M. Review of the psychometric properties of the Diabetes Self-Efficacy Scale: Australian longitudinal study. Nurs Health Sci. 2003;5(4):289-97.

50. Sturt J, Hearnshaw $\mathrm{H}$, Wakelin M. Validity and reliability of the DMSES UK: a measure of self-efficacy for type 2 diabetes self-management. Prim Health Care Res Dev. 2010;374-81.

51. Ajzen I. The theory of planned behaviour: Reactions and reflections. Psychol Health. 2011;26(9):1113-27.

52. Rushforth B, McCrorie C, Glidewell L, Midgley E, Foy R. Barriers to effective management of type 2 diabetes in primary care: qualitative systematic review. Br J Gen Pract. 2016;66(643):e114-127.

53. Ambrosio L, Portillo MC, Rodriguez-Blazquez C, Rojo JM, Martinez-Martin P, Group E-PV, et al. Influencing factors when living with Parkinson's disease: a cross-sectional study. J Clin Nurs. 2019;28(17-18):3168-76.

54. Rothman M, Burke L, Erickson P, Leidy NK, Patrick DL, Petrie CD. Use of existing patient-reported outcome (PRO) instruments and their modification: The ISPOR Good Research practices for evaluating and documenting content validity for the use of existing instruments and their modification PRO Task Force report. Value in Health. 2009;12(8):1075-83.

55. Beléndez M, Hernández-Mijares A, Marco J, Domínguez JR, Pomares FJ. Validation of the Spanish version of the Problem Areas in Diabetes (PAIDSP) Scale. Diabetes Res Clin Pract. 2014;106(3):e93-5.

56. Balcázar-Nava P, Gurrola-Peña GM, Moysén-Chimal A, Urcid-Velarde S, Garay-López JC, Velasco-Fuentes MC, et al. Análisis de las propiedades psicométricas de la diabetes empowerment scale (des-lf-s) en español. Duazary. 2016;13(2):95-104.

\section{Publisher's Note}

Springer Nature remains neutral with regard to jurisdictional claims in published maps and institutional affiliations.
Ready to submit your research? Choose BMC and benefit from:

- fast, convenient online submission

- thorough peer review by experienced researchers in your field

- rapid publication on acceptance

- support for research data, including large and complex data types

- gold Open Access which fosters wider collaboration and increased citations

- maximum visibility for your research: over $100 \mathrm{M}$ website views per year

At BMC, research is always in progress.

Learn more biomedcentral.com/submissions 